\title{
Conceptual Model of Effect and Form of Architecture and Structures
}

\author{
NEJATI, F; *HABIB, F; SHAHCHERAGHI, A \\ ${ }^{1}$ Department of Civil, Architecture and Arts, Science and Research branch, Islamic Azad University, Tehran, Iran. \\ Email: archiffania@yahoo.com \\ *Corresponding Author Email: f.habib@srbiau.ac.ir
}

\begin{abstract}
In addition to having the most stability, the first task that every building has to do is having the economic factor, which is one of the concerns of the builders. One of the tools for the advent of architectural form is the structure. This is despite the fact that the limitless artistic thinking has very little unity with numerical and enclosed numerical thinking in the framework of structural engineering math. The date of the interaction between the architecture and the structure implies that the industrial revolution and the consequences are considered as a major event contributed to the further disruption of the relationship between architecture and structural engineering. In many studies, the form of architecture, structure, and nature have been distinctly examined, but in the present study, it was tried to link these two relatives, structures and architectures from the form in nature using technology. First, the evolution of structural and architectural harmony in different historical periods was studied. Then, we focused on natural patterns such as human, plant, and animal structures and finally, works by the Spanish architect, Gullart, was analyzed as an external case study. Regarding the above, this study has achieved a model and a strategy to enhance the quality of construction and interaction of structure and architecture using the structural structure in the existing forms in nature.
\end{abstract}

\section{DOI: https://dx.doi.org/10.4314/jasem.v22i8.17}

Copyright: Copyright $\odot 2018$ Nejati et al. This is an open access article distributed under the Creative Commons Attribution License (CCL), which permits unrestricted use, distribution, and reproduction in any medium, provided the original work is properly cited.

Dates: Received: 05 June 2018; Revised: 22 July: 2018; Accepted: 12 August 2018

Keywords: Architecture, Structures, Nature, Architectural and Structural Interaction

Once upon a time, Earth was created and all the creatures began to live in it and all creatures naturally started making shelter for themselves and man as one of the creatures on earth began to build cottages and shelter using natural materials inspiring from natural constructions such as the birds' nest and other animals' shelter. They did not pay attention to the beauty of the building as much as its structure and stability. With time and technology advancement, many opportunities have been created for human beings to have more diversity in shelter design. Architecture begins when man uses a structure like a tent as a circular house (Vahedi, 2009).Some scholars believe that the nature is the best source of inspiration for people to learn. They believe that the natural organism does whatever the man wants to do without destroying the environment and the future. In the history of architecture it is clear that the architecture began to take advantage of nature directly or thought of it but with the advent of technology and its impact on human life and architecture, they went away from nature every day. Fortunately, as far as nature was concerned, architects and engineers felt that by forgetting the nature, their products would greedily destroy the nature and we cannot survive without nature, so we have to go back to nature and find the solution to be with nature. The date of the interaction between the architecture and the structure implies that the industrial revolution and its consequences are considered as a major event contributed to the further disruption of the relationship between architecture and structural engineering. On the other hand, engineering education schools started working; The Paris School of Fine Arts was founded, which led to separation of architecture and building technology (HashemNejad and Soleimani 2007). In ancient Iran, the architecture and the structure were also a unit major, which there was no concept of separation, while in the contemporary era; the structure and architecture are completely separate from each other (Baghai, 2009). This study aimed to achieve a structure-based structure design inspired by nature.

Theoretical basics: Many architects believe that nature can be a powerful source, where Frank Lloyd Wright says: Study nature. Love nature and approach it. It will never fail you. Or Louis Kahn says: It's my feeling that if all the plants and phenomena disappear, there is still a sun to shine and the rain to pour so we always need nature, but it does not need us. As Adorno says art and nature are not separable. Adorno defines natural beauty as a manifestation of a non-instrumental relationship with nature as a result of the profound 
observation of nature and defines the aesthetic experience of nature as the experience of art and intellectual imagery. Hegel expresses beauty in two types: first, natural beauty, and second, artistic beauty. Christopher Alexander says there is a deeper relationship between nature and human minds than what is claimed by modern science and architecture. In the past, architecture and urbanization were unknowingly developing with the order of nature, that is, with the fractal order. Man-made artifacts were also fractal. Wright considers the concept of beauty in organic architecture. The presence of human in the natural environment can lead to psychological recovery and reduce individual stresses. If the relationship between man, nature and the artifact environment is ideal, mental health and well-being of the community also reaches a promising quality (Shahcheraghi and BandarAbad 2015).

One of the most fundamental researches on the impact of nature on human body and soul is the research by Ian McHarg, which published the results as the design with nature. The methodology is based on overlapping GIS layers and improved it and claimed that the answer must be reflected in the set of maps. The statistics of physical, psychological and social illnesses are exactly proportional to the decline in the presence of nature in the city. In this study, the relationship between humans and the environment around them was examined and made them to accept that their life is blended with the forces of nature, both in disease and in health. The human being is surrounded by the nature. Theorists such as Bell and Spirn analyzed the hidden dimensions and indirect signs of nature, such as diversity, complexity and mystery and attempted to provide patterns to identity man made environments through the inspiration by natural processes. Simon Bell concludes that linking to nature based on experience and practice can reduce the sense of alienation in bio-complexes. In the meantime, phenomenologist such as Schultz and Pallasmaa consider the presence of nature to be effective in this based on the views of Heidegger, Montgomery and Husserl (Shahcheraghi and BandarAbad 2015).

The effect of nature on architecture is defined by any processes in every architectural school. The conception on the complexities of nature by many contemporary architecture schools is perceptions of form and appearance. But the important point is to understand the basis of this complexity.

How to form a formation: Most construction workers believe that the process of finding a suitable form of building requires collaboration between the civil engineer and architect; both professions would be much more successful if they have a better and deeper understanding of one another's knowledge. Finding the appropriate form is divided into large groups (Larsen and popovic, 2016).

Table 2: Consolidation of Architectural and Structural Form. Reference: Research findings

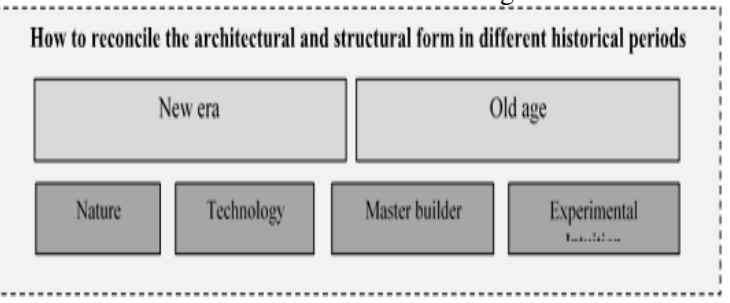

In 2006, a series of activity diagrams was published, in which a number of works show that many leading architects found this basic point that each physical environment is affected by the behavior of users. In fact, these architects first consider the ethos in the process of designing the environment considering the cultural and social factors of users and then they work with architectural ideas to design flexible or multifunctional environments. In such environments, only one particular performance, activity or behavior is not imposed on the environment but they also have a sense of freedom in their behavior and activities and residents contribute to shaping the environment and creating a sense of place. Thus, in such environments, not only is not the single-sound environment but also there are other voices heard because it has a polyphonic property; this creates a dialogue between the resident and the place (Shahcheraghi and BandarAbad 2015).

\section{RESULTS AND DISCUSSION}

The formation of structure in architecture: Case Study, Guallart Works: Vinaros is a city on the Mediterranean coast of Spain near the Ebro delta between Barcelona and Valencia. Clearly, rocks, seas and stones have a unique beauty. According to the rocks' size by the sea, the project reached a hexagon and achieved the project's original form with parametric software. In this area, there is abundant conglomerate rock that has been eroded by tidal (Taghizadeh, 2008).

International and international exhibitions such as the Olympic Games are the events that play an important role in the consolidation of the political and economic situation of a country. Wroclaw in the south of the Netherlands near the German border as a hoping place has attracted the attention of the world. The area is in a crossroads, where two rivers approach with a historical land with cultures and different empires 
The key theme of this exhibition is the culture of leisure in the world economy. The exhibition wanted to have a topography based on the form of a mountain. The topography of the mountain is based on get sunlight by photovoltaic panels to store energy for the building.

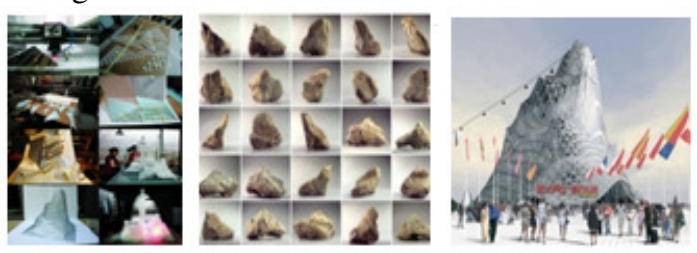

Fig. 5: The Netherlands International Exhibition, Guallart, reference: www. Guallart.com

Spanish booth in the Shanghai Exhibition project is recognizable as a space for Spanish culture. The exhibition wants to develop the motto of better life, better city, which is inspired by fruit trees in Spain, especially lemons and oranges. Trees have an open structure that allows for many vacant spaces for exhibit activities and also allows grouping because of their expandable three dimensional structures. Trees were made of metal sheets by laser cutting. Solar panels were considered for energy storage at the top of trees (Taghizadeh, 2008).
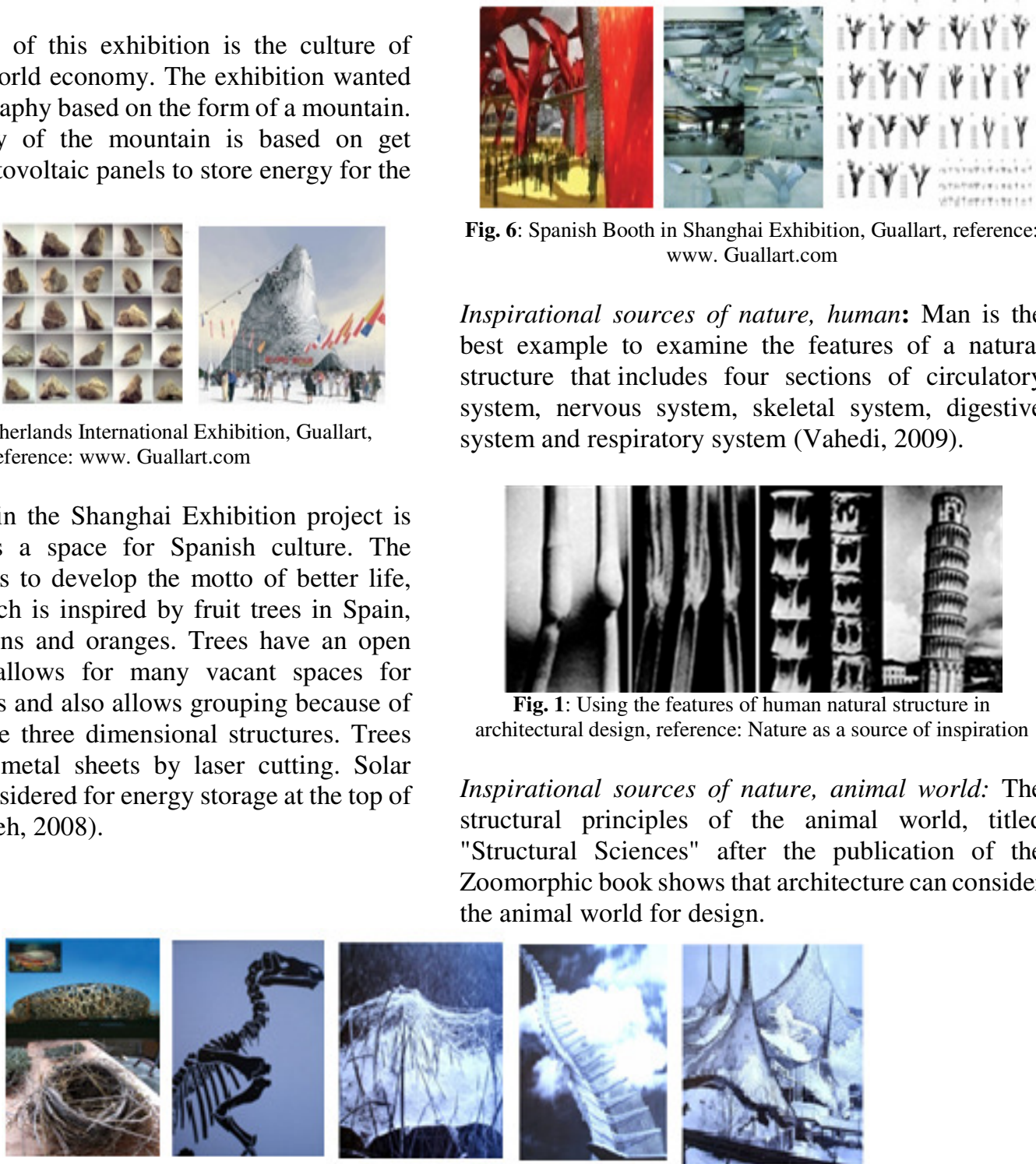

Fig. 6: Spanish Booth in Shanghai Exhibition, Guallart, reference: www. Guallart.com

Inspirational sources of nature, human: Man is the best example to examine the features of a natural structure that includes four sections of circulatory system, nervous system, skeletal system, digestive system and respiratory system (Vahedi, 2009).

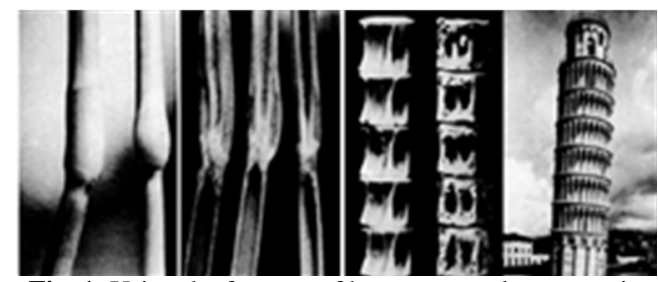

Fig. 1: Using the features of human natural structure in architectural design, reference: Nature as a source of inspiration

Inspirational sources of nature, animal world: The structural principles of the animal world, titled "Structural Sciences" after the publication of the Zoomorphic book shows that architecture can consider the animal world for design.
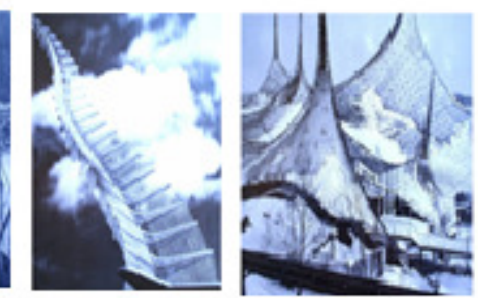

Fig. 2: Animal body structure an inspiration for architects, reference: Nature as a source of inspiration

In the body of a livestock and its ossification from a mechanical view, the weight of the animal is transmitted to the ground through the legs. In this regard, the structure of an animal can be likened to an engineering structure such as a bridge. Such a structure includes the head, neck, and tail of the animal. Modeling the animal activity is also discussed in many cases. The Beijing Olympic Stadium is a good example of birds' nest. The external structure is designed as a set of large vessels. Structural elements hold each other completely and cross each other as a grid like birds' nest woven with small branches. The animals' structures are the complete existential phase of nature that in addition to life, they also have tangible moves, which these two features distinguish them from inanimate organisms and plants. The constituent parts of animals, such as bones, are mostly multifunctional, which can convert electrical effects into mechanical effects and vice versa (piezoelectric property). This feature has a significant role in the growth and healing of bone fractures. The compressive effects stimulate estrogenic cells to produce bone (in the compression region) and tensile effects cause bone loss (in the tensile region). So, the bone forms in the direction of the force. That is, the bone changes its shape so much (by forming and eliminating the bone), which decreases its bending anchor and placed along the force that is pressurized. Due to continuous movement, animal forms have stronger relationships with plant forms. All organs of 
the body coordinate during movements and cause a balance in the general structure. The role of bone in the animal body is mechanically similar to that of a building's skeleton. Each structure requires a structural skeleton for equilibrium and stability. Skeleton of the living organism with the help of tensile elements such as muscles and tendons and connections such as cartilage make a set that does not come up with the most complete architectures.

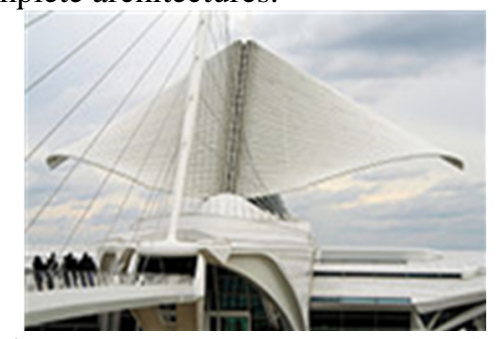

Fig. 3: Milwaukee Art Museum, Calatrava, reference: www.memaran.com

Inspirational sources of nature, the world of plants: According to Fisher in 1964, the structure of the membrane in the nature is the tropical lily-leaf skeletal, which was modeled for Crystal Palace and this was a turning point in architecture to a new direction for development. The Bionic architecture, a global work, was started in 1993 that uses different ideas of nature for architecture. One of the most important ideas is the technique that nature uses for birth. The Bionic architecture is defined in 2 titles; an architecture that imitates the appearance and function of the life of phenomena and the architecture that imitates the appearance of the structure and its function (Hedayat and Farnaz, 2011). Another title for the Bionic architecture is the link between biology and technology. Projection of the formation of the bionic architecture is a simple retreat to nature. In the new world, the understanding of nature and the computational ability of simulating the natural process is possible (Vahedi, 2009).

Each of them has different sections such as fitness, inheritance, the choice of Richard Bonser in the biometric building propose a question why it should be copied from nature, and it comes to the conclusion that How nature teaches us to improve sustainability. Plant structures of arid plants are classified into two main types of vascular and non-vascular. The system of vascular plants consists of xylem and phloem, which xylem carries water and soluble materials and phloem transfer photosynthetic products. In addition to transfer material, phloem system such as vertical columns extends continuously from roots to the leaves.

Inspiration from vascular Plants and Trees' braches in Designing Architectural Structures: Non-living natural structures of natural forces that cause the emergence and transformation of natural building forms are created by existential manifestations of the planet, or have a general nature. The building forms in the solid core of the earth are generally caused by the effects of these forces. The fissures on the earth, depending on the roots and the effect of the forces have various forms. In addition to being shaped by external forces, a non-living natural form still tries to maximize efficiency with minimal components, such as soap bubbles that in a two-dimensional view always bubbles three adjoin and creates irregular triangular networks, which are triangular networks of one of the natural geometries and operate on the basis of minimum components and maximum efficiency.

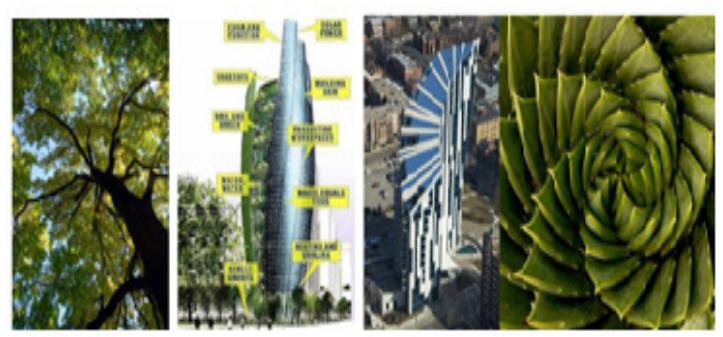

Fig. 4: Inspiration from Plant Structure in Architectural Design, reference: Nature as a source of inspiration

Processes of the Nature Emergence: There is any form without performance in the nature. The environmental condition in which nature is formed is very important. There is a harmony between the shape and function of the material world. The effect of nature on architecture is considered in any architectural school. The conception on the complexities of nature by many contemporary architecture schools is perceptions of form and appearance. But the important point is to understand the basis of this complexity. The effect of nature on architecture is defined by any processes in every architectural school. Nature can be a great inspiration for designers. The benefits of nature inspiration are as follows (Sharghi and Ghanbaran, 2015).

Table 3: The process of the nature emergence. Reference: author findings

\begin{tabular}{|l|lr|lr|l|}
\hline \multicolumn{5}{|l|}{ Forms in nature appear by one of the following processes. } \\
\hline $\begin{array}{l}\text { Processing is } \\
\begin{array}{l}\text { controlled by human } \\
\text { demand }\end{array}\end{array}$ & $\begin{array}{l}\text { A process of genetic } \\
\text { guidance } \\
\text { environmental conditions }\end{array}$ & $\begin{array}{l}\text { A process that is related to physical } \\
\text { and chemical laws in nature and } \\
\text { environmental conditions }\end{array}$ & $\begin{array}{l}\text { Uncontrolled } \\
\text { process }\end{array}$ \\
\hline
\end{tabular}


Table 4: reasons of Benefiting from Inspiration by Nature for Designers. Reference: author findings

\begin{tabular}{|l|l|l|l|l|l|}
\hline $\begin{array}{l}\text { details with } \\
\text { various scale in } \\
\text { nature }\end{array}$ & $\begin{array}{l}\text { Preserving } \\
\text { identity } \\
\text { nature }\end{array} \quad$ in & $\begin{array}{l}\text { lompatibility } \\
\text { with the } \\
\text { climate }\end{array}$ & $\begin{array}{l}\text { Natural structures have the } \\
\text { process of load sensing and } \\
\text { modification cycles }\end{array}$ & $\begin{array}{l}\text { Geometry alden } \\
\text { poportions }\end{array}$ \\
\hline
\end{tabular}

Table 5: Methods of Inspiration by Nature Reference: author findings

\begin{tabular}{l|l|l|l|}
\hline $\begin{array}{l}\text { Inspiration by the rules of } \\
\text { nature: The best inspiration }\end{array}$ & $\begin{array}{l}\text { Meaning inspirational by nature } \\
\text { metaphorical and the meaning: TWA } \\
\text { by the nature is to maintain } \\
\text { airport in the United States with the } \\
\text { the existing structure against } \\
\text { the entered loads and forces }\end{array}$ & $\begin{array}{l}\text { Thesign by nature forms: } \\
\text { example. }\end{array}$ & $\begin{array}{l}\text { nature. Maintain existing } \\
\text { structure against loads and } \\
\text { forces }\end{array}$ \\
\end{tabular}

Methods of Inspiration by Nature Structure: Nature always tries to use tensile stresses in its structures as much as possible and does not use bending stresses, except where its structure has a layered nature. Basically, all natural structures have a layer texture. That is, their surfaces and volumes have been created by layers. Layer nature causes only tensile or compressive reactions in natural forms, because bending means vanity in the use of materials and in nature nothing has been created in vain. Over the past hundred years, the evolutionary process of structures has been the gradual movement of flexural structures toward tensile and compressive structures, which has led to the formation of tent and shell structures in architecture.

Resistance to forces with flexibility and deformation: This method is widely observed in natural structures and has a high flexibility. For example, many birds prefer to make nests on soft, thin branches of trees, because the branches have more flexibility and the probability of their break will be less. Such a procedure causes that the structure has the best response to the resistance while less material is consumed.

Escape from the Force: This method is also one of the methods of coping with the forces of nature and in fact, the basis of this is the reduction of the amount and intensity of force. For example, trees with their bend can pass some of the forces of heavy winds from above and thus, the amount of force on their trunks decreases.

Using intruders against each other or on their own: trees bend when wind blows and save some of the wind power in the form of potential energy and discharged part of this force against the flow of wind by reciprocating movements. The position of tree branches is such that the weight of one side of the tree holds the other side of the tree and vice versa. Similar this behavior in the architecture can be seen in deck and main span of the Alamillo Bridge in Spain designed by Kalatrava. In the designing and construction of this bridge, the equilibrium between the deck and the span has been established on nonsymmetrical aesthetic principles, so that the main deck and span a factor to hold each other.

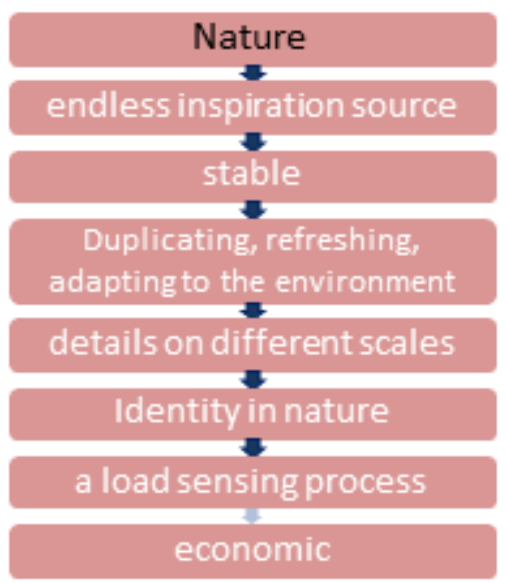

Diagram No. 2: reasons of Benefiting from Inspiration by Nature for Designers. Reference: author findings In architecture history, it's clear that architecture began to take advantage of nature directly, or the idea of it to build. However, with the advent of technology and its impact on human life and architecture, a variety of tools and idea from nature had been provided for designers. The nature is the endless inspiration source that can contribute to the mental recovery of humans. In addition, the use of natural structure can lead to constructive interaction between a structure and an architectural form. A coherent and integrated approach to create a structure is inspired by nature. Based on global experiences, deep attention to the natural structure and analysis of structural forms shows that harmonious architectural forms can be obtained using parametric software and analysis of the nature structure.

Finally, it can be said that the nature has always been a model for architectural and structural designers. Perhaps inspired by nature (Fig. 2) is the interface between designers and architects; a living creature is dependent on its ability to respond to the environment for survival. The life of a structure is dependent on its 
relation to nature. Given that the form is influenced by nature as well as the process that has developed in the past and present time, it can be guessed that in the future, construction inspired by nature will be carried out more quickly than ever.

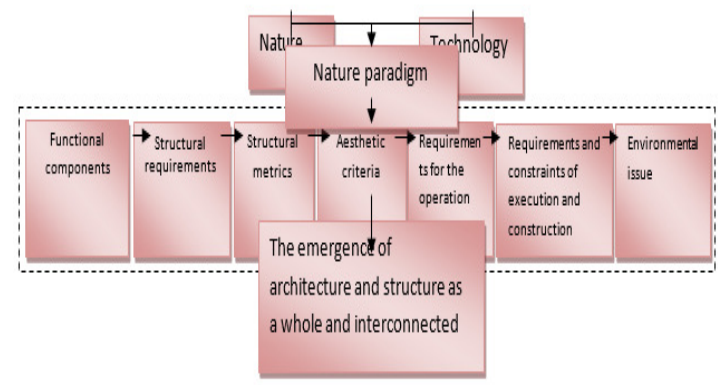

Fig. 11: diagram Formation Trend and Aesthetic Form

\section{REFERENCES}

Baghai, A (2009). The role of structures in the structure of contemporary architectural aesthetics", City identity. (Persian)

Eynifar, A (2007).The Role of Architecture: The Role of Behavioral Sciences in Environmental Design, Tehran University, first edition. (Persian)

Golabchi, M (2012). Applied static for students of architecture and civil engineering, Fifth Edition, Tehran University Press. (Persian)

Golabchi, M; Mazaherian, H (2009). Modern Construction Technologies, Fourth Edition, Tehran University. (Persian)

HashemNejad, H; Soleimani, S (2007). The Need for Structural and Architectural Synthesis in Contemporary Architecture, The Art of Fine Arts, 30(1): 1-15. (Persian)

Hedayat, Sh; Farnaz, M (2011). Recognition Nature Related Concepts in Bionic Architecture and Their Effects on Contemporary Architecture, International Conference on Nanotechnology and Biosensors, IACSIT Press, Singapore. 4(9):43-56. Http:// www.guallart.com, may 2017. https://sciarc.edu/people/faculty/hernan-diaz-alonso/

Larsen, O; popovic, T (2016). Conceptual structural design, London Thomas Telford

Lauren, B; Alessandre, B; Neil, K; William, F; baker, G; Paulino, H (2014). Connecting architecture and engineering through structural topology optimization, engineering structures. 4(6)11-23.

Louise, P (2017) structure as architecture, Jonas Taljsten, Lund University, Master dissertation

Macdonald, A (2001). Structure and architecture, Department of Architecture University of Edinburgh

Mehdinezhad, MR; Nikbakht, H; Jafari, A (2013). Functional Design in Structural Engineering and its Influence on Architectural Design, J. Basic. Appl. Sci. Res. 1(2)23-34.

Rohi, AR (2005). Theoretical Basis, First Edition, Asr Kanakash Publications. (Persian)

Roohi, AR (2013). Contemporary Architecture, Fourth Edition, Asr Kanakash Publications. (Persian)

Shahcheghi, A (2005). Architecture and Technology of the Age of Communication", Computer Architecture Quarterly. PP: 112(Persian)

Shahcheraghi, A; BandarAbad, A (2015). Inside the Environment, First Printing, Tehran University Jihad. (Persian)

Sharghi, A; Ghanbaran, A (2015).Theories of Nature in Architectural Design, Environmental Science and Technology. (Persian)

Taghizadeh, K (2008). Functional Design in Structural Engineering and its Influence on Architectural Design, Fine Arts. City of dreams, Macau, March 2016 making the vision viable, the structural engineer

Vafamehr, M (2012). Architectural and Technology Interaction, First Edition, Rose Publishing, Season One (Persian).

Vahedi, A (2009). Nature as a source of inspiration of architectural conceptual design, Mediterranean university

York, R (2007). Aesthetic in architecture, translated by Jahanshah Pakzad, shahid Beheshti University, The Role of Structure in Creating Architectural Space, 2015, Current World Environment,

Zarkesh, A (2008). The quality of education and professional work in creating the harmony between space and structure in the contemporary Western art", Beautiful Arts magazine. (Persian) 